\title{
Absence of Tolerance to Hypotensive Effects of Clonidine in Spontaneously Hypertensive Rats
}

\author{
Tomohiro Naruse, Ritsuko Ishii and Takeshi Tagawa \\ Central Research Laboratories, Maruho Co., Ltd., 1-8-23 Oyodo Naka, Kita-ku, Osaka 531, Japan \\ Received December 13, 1994 Accepted February 24, 1995
}

\begin{abstract}
Development of tolerance to the hypotensive effects of clonidine was investigated in spontaneously hypertensive rats (SHR). Clonidine $(125 \mu \mathrm{g} / \mathrm{kg} / \mathrm{day})$ was administered subcutaneously for 5 weeks using an osmotic infusion pump. During the whole infusion period, significant hypotensive and bradycardic effects were observed. Plasma clonidine concentrations were maintained relatively constant at about $2 \mathrm{ng} / \mathrm{ml}$ during the infusion period. On termination of treatment with clonidine, both the blood pressure and heart rate rapidly recovered to the control levels. These findings suggest that clonidine does not cause tolerance to its hypotensive effects in SHR with the present administration regimen.
\end{abstract}

Keywords: Tolerance, Hypotensive effect, Clonidine

Tolerance to the analgesic effects of clonidine has been reported to develop in experimental animals $(1-3)$. Apart from the analgesic effects, long-term administration of clonidine in humans has been reported to cause tolerance to its hypotensive effects (4). As experimental evidence in support of this finding, tolerance to the hypotensive effects of clonidine has been also reported in normotensive rats (5) and spontaneously hypertensive rats (SHR) (6). However, several experimental studies have demonstrated no development of tolerance to the hypotensive effects of clonidine in the same species $(7-10)$. These experimental findings on tolerance to the hypotensive effects of clonidine are controversial because administration regimens and/or routes and observation periods in tolerance studies of clonidine tend to vary extensively. With regard to administration, Salzmann (7) has employed compulsive oral administrations; Koike et al. (8) and Sannajust et al. (10) resorted to mixing clonidine with food and water; Thoolen et al. (9) selected continuous subcutaneous administration with an osmotic infusion pump. Furthermore, the observation period can either be 12 days $(9$, $10)$ or 3 to 5 weeks $(7,8)$. On the other hand, there are few reports describing the relationship between the hypotensive effects and plasma levels of clonidine in SHR on development of tolerance to the hypotensive effects of clonidine. We have already reported that the hypotensive effects of clonidine are closely related to its plasma levels in SHR (11). In addition, because the elimination half-life of clonidine is short in SHR (11), it is necessary to determine the changes in both the hypotensive effects of clonidine and its plasma levels throughout long-term administration when tolerance to the hypotensive effects of clonidine is studied in SHR. We have already confirmed that the method for administration of clonidine using an osmotic infusion pump is suited to maintain plasma levels in SHR (12). Therefore, the present experiment was performed to clarify the relationship between the development of tolerance to the hypotensive effects of clonidine and plasma levels of clonidine in SHR administered subcutaneously with an osmotic infusion pump for a 5-week period.

Male SHR (14-week of age) weighing 249-333 g were used in the present study. Prior to clonidine (clonidine hydrochloride; Daiwa Pharmaceutical Co., Ltd., Toyama) infusion with an osmotic infusion pump (Model 2002, reservoir volume of $200 \mu 1$; Alzet, CA, USA), systolic blood pressure and heart rate were measured in each animal by the tail-cuff method using a programmable sphygmomanometer (PS-100; Riken Kaihatsu, Tokyo). Under ether-anesthesia, the osmotic infusion pump (125 $\mu \mathrm{g} / \mathrm{kg} / \mathrm{day}$, as free base) was implanted subcutaneously in SHR showing a mean systolic blood pressure and heart rate of $203.6 \pm 4.2 \mathrm{mmHg}$ and $364.8 \pm 12.0$ beats $/ \mathrm{min}$, respectively $(n=8)$ on day 1 of the experiment. Thereafter, the infusion pump was replaced at 1-week intervals for 5 weeks under ether-anesthesia. Osmotic infusion 
pumps containing saline solution were implanted and replaced in the control animals that had a mean systolic blood pressure and heart rate of $211.1 \pm 6.4 \mathrm{mmHg}$ and $353.8 \pm 11.0$ beats $/ \mathrm{min}$, respectively $(n=8)$, in a similar manner to the clonidine-infused rats. During the 5-week administration period, systolic blood pressure and heart rate were measured weekly before replacement of the new osmotic infusion pump. To study the recovery of the hypotensive effects of clonidine after the 5-week infusion period, systolic blood pressure and heart rate were measured at 4, 8, 24 and $72 \mathrm{hr}$ after removal of the infusion pump under ether-anesthesia. To determine plasma clonidine concentrations, 23 SHR were used in a separate study. An osmotic infusion pump containing clonidine solution at the same dosage was implanted in each animal in a similar manner as described above. After laparotomy with a median incision under ether-anesthesia at $1(n=7)$, $3(n=8)$ and 5 weeks $(n=8)$, arterial blood samples of $7-8 \mathrm{ml}$ were collected from the abdominal artery with heparinized syringes. Plasma samples were isolated by centrifugation $\left(1500 \times \mathrm{g}\right.$ for $15 \mathrm{~min}$ at $\left.4^{\circ} \mathrm{C}\right)$ and stored at $-80^{\circ} \mathrm{C}$ until assayed. Analyses of plasma clonidine con- centrations were performed by gas chromatographymass spectrometry (GC/MS) (Model 5890, Series 2 and Model 5971A; Hewlett-Packard, North Hollywood, CA, USA) (13). Data are expressed as means \pm S.E. Changes in the systolic blood pressure and heart rate were presented as differences from the baseline and expressed in $\mathrm{mmHg}$ and beats/min, respectively. Statistical analyses for systolic blood pressures and heart rates were performed by the unpaired Student's $t$-test. Statistical analyses for plasma concentrations of clonidine were performed by dispersion analysis by the Bartlett method. With regard to the plasma concentrations, the distribution was not uniform. Therefore, they were analyzed by the Kuraskal-Wallis test. When there were intergroup differences in the plasma concentrations, a multiple comparison was made by Bonferroni's parametric or nonparametric method. $P$ values of less than 0.05 were considered statistically significant.

Significant and stable hypotensive and bradycardic effects were observed during the clonidine infusion (Fig. 1). Following the termination of treatment with clonidine, systolic blood pressure and heart rate rapidly re-
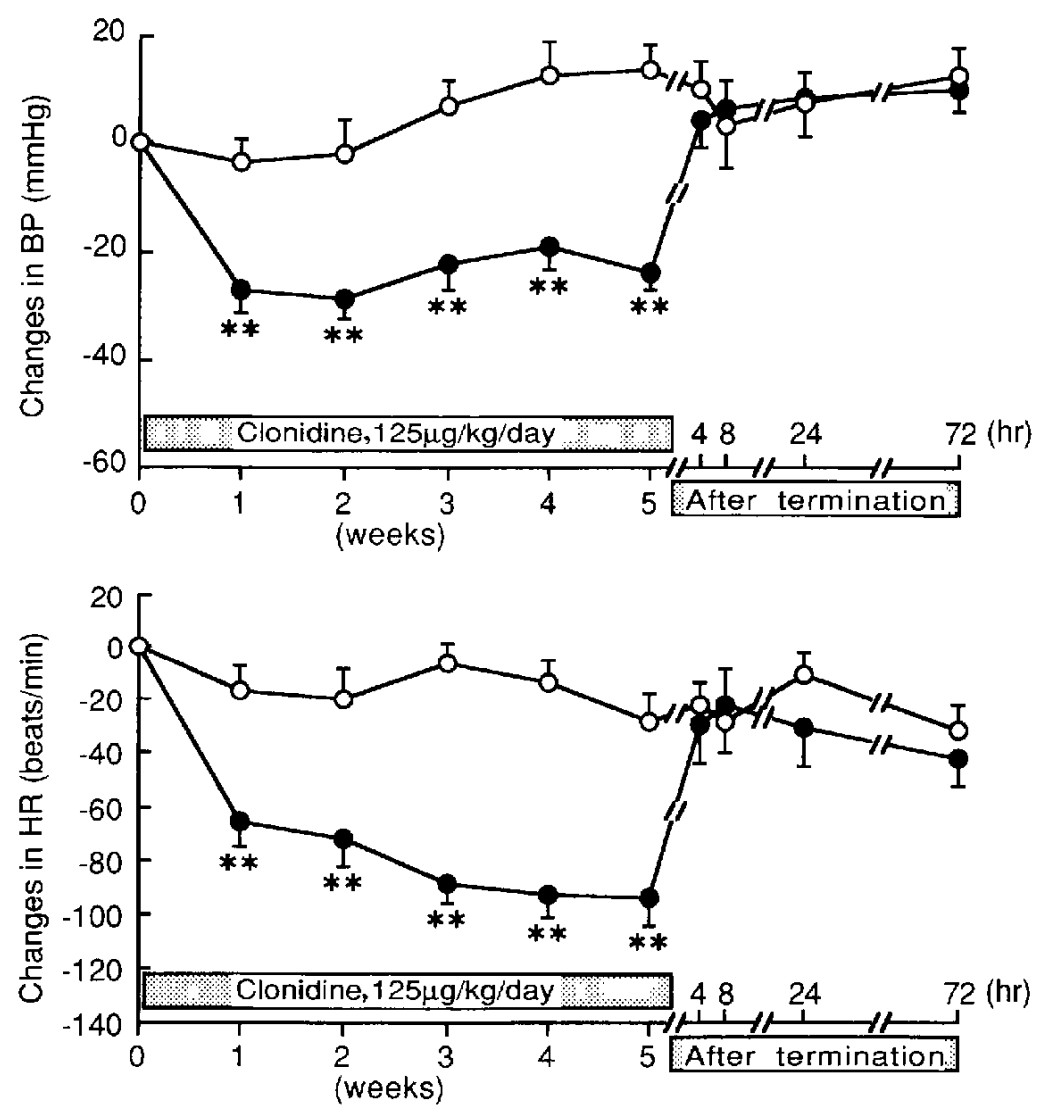

Fig. 1. Effects of continuous infusion of clonidine for 5 weeks on the blood pressure and heart rate in spontaneously hypertensive rats (SHR). Systolic blood pressures (BP) and heart rates (HR) were measured during the infusion and after the infusion of vehicle $(O)$ or clonidine at a dose of $125 \mu \mathrm{g} / \mathrm{kg} / \mathrm{day}(\mathrm{O})$. Changes in $\mathrm{BP}$ and $\mathrm{HR}$ are presented as differences from the baseline. Each point and vertical bar represent the mean \pm S.E. of 8 SHR. ${ }^{* *}$ : Significantly different from the control, $P<0.01$. 


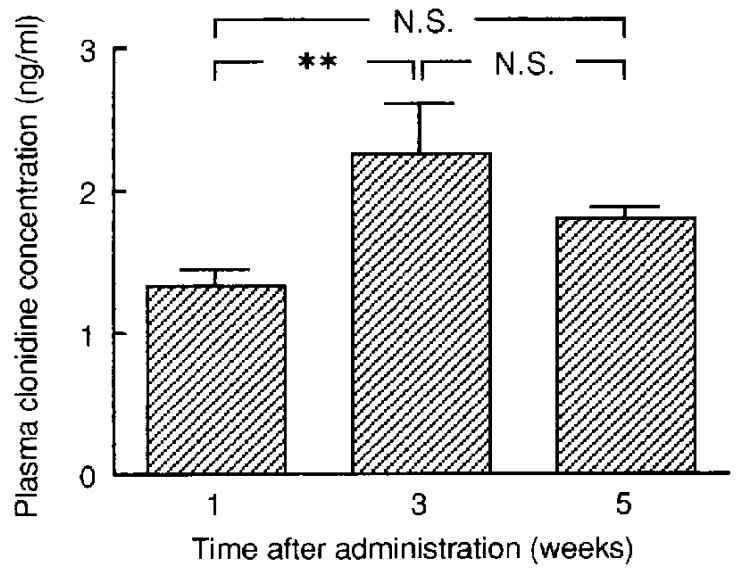

Fig. 2. Plasma clonidine concentrations during continuous infusion of clonidine for 5 weeks in spontaneously hypertensive rats (SHR). Clonidine was administered as described in Fig. 1. Each arterial blood sample of $7-8 \mathrm{ml}$ was collected from the abdominal artery under ether-anesthesia at $1(n=7), 3(n=8)$ and 5 weeks $(n=8)$. Each column and vertical bar represent the mean \pm S.E. ${ }^{* *}$ : $\mathrm{P}<0.01$. N.S.: Not significant

covered to the control levels at $4 \mathrm{hr}$. However, slight tremor and diarrhea were observed at 4 and $8 \mathrm{hr}$, and these symptoms disappeared at $24 \mathrm{hr}$ post-termination of clonidine infusion.

The plasma clonidine concentration reached a maximum at 3 weeks and tended to decrease at 5 weeks (Fig. 2). The concentration was considered to be kept in a range of 1 to $2 \mathrm{ng} / \mathrm{ml}$ through the infusion period.

Recently, we have confirmed that the half-life of clonidine in plasma is $3 \mathrm{hr}$ in SHR after oral administration (11). Therefore, it is very important to investigate the plasma concentrations in relation to the hypotensive effects during the chronic treatment with clonidine in SHR. A previous study has indicated that continuous subcutaneous infusion of clonidine at $125 \mu \mathrm{g} / \mathrm{kg} /$ day causes stable hypotensive effects accompanying relatively constant plasma levels of $2-3 \mathrm{ng} / \mathrm{ml}$ for 8 days (12). The present findings confirm that hypotensive effects and plasma levels of clonidine are stable even though the infusion period is extended for 5 weeks. These findings also suggest that clonidine given by the present regimen does not cause tolerance to its hypotensive effects in SHR. Davidov et al. (14) have reported that tolerance to the hypotensive effects of clonidine in humans is mainly due to retention of sodium and extracellular fluid volume. In fact, Hoobler and Sagatsume (15) have observed a lower incidence of tolerance in humans when clonidine is administered with a diuretic. In the present study, it is unclear whether it causes the retention of sodium or not, since we did not determine the sodium balance during the clonidine treatment.
Considering the clinical aspects of tolerance to the hypotensive effects of clonidine, further studies will be required to clarify the relationship between sodium balance and hypotensive effects of clonidine in SHR. Certain withdrawal symptoms such as a transient increase in blood pressure and tachycardia are not observed in the present study. These symptoms have been observed by a higher dose $(250 \mu \mathrm{g} / \mathrm{kg} /$ day $)$ of clonidine that elicited more remarkable hypotension with higher plasma levels exceeding $3 \mathrm{ng} / \mathrm{ml}$ (13). Thus, the withdrawal symptoms by clonidine may be dependent on its plasma levels which are related to its hypotensive effects.

Our findings indicate that continuous subcutaneous infusion of clonidine ( $125 \mu \mathrm{g} / \mathrm{kg} /$ day) for 5 weeks induces persistent hypotension accompanied by relatively constant plasma concentrations in SHR. These findings suggest that clonidine does not cause tolerance to its hypotensive effects within 5 weeks when given by the present regimen to SHR.

\section{REFERENCES}

1 Paalzow G: Development of tolerance to the analgesic effect of clonidine in rats. Cross tolerance to morphine. Naunyn Schmiedebergs Arch Pharmacol 304, 1-4 (1978)

2 Chance WT: Clonidine analgesia: Tolerance and cross-tolerance to autoanalgesia. Life Sci 33, $2241-2246$ (1983)

3 Solomon RE and Gebhart GF: Intrathecal morphine and clonidine: antinociceptive tolerance and cross-tolerance and effects on blood pressure. J Pharmacol Exp Ther 245, 444-454 (1988)

4 Onesti G, Bock KD, Heimsoth V, Kim KE and Merguet P: Clonidine: A new antihypertensive agent. Am J Cardiol 28, 74-83 (1971)

5 Laverty $R$ and Taylor M: Behavioural and biochemical effects of 2-(2,6-dichlorophenylamino)-2-imidazoline hydrochloride (St 155) on the central nervous system. Br J Pharmacol 35, 253-264 (1969)

6 Mastrianni JA and Ingenito AJ: Acute tolerance to clonidine hypotension and bradycardia in normotensive and hypertensive rats. Pharmacol Res Commun 17, 865-872 (1985)

7 Salzmann R: The effects of treatment and of withdrawal of treatment with guanfacine and clonidine on blood pressure and heart rate in normotensive and renal hypertensive rats. J Pharm Pharmacol 31, 212-216 (1979)

8 Koike Y, Togashi H, Shimamura K, Yomaida I and Saito H: Effects of abrupt cessation of treatment with clonidine and guanfacine on blood pressure and heart rate in spontaneously hypertensive rats. Clin Exp Hypertens 3, 103-120 (1981)

9 Thoolen MJMC, Timmermans PBMWM and van Zwieten PA: Guanfacine and clonidine: Antihypertensive and withdrawal characteristics after continuous infusion and its interruption in the spontaneously hypertensive and normotensive rat. Naunyn Schmiedebergs Arch Pharmacol 319, 82-86 (1982)

10 Sannajust F, Julien C, Barres C, Cerutti C, Koenig-Berard E and Sassard $\mathbf{J}$ : Cardiovascular effects of rilmenidine, a new alpha 2-adrenoceptor agonist, and clonidine in conscious spontaneously hypertensive rats. Clin Exp Pharmacol Physiol 16, 


\section{$837-848$ (1989)}

11 Ishii R, Naruse T, Tagawa T, Yamahata T, Dote S, Hamada K, Ishida T, Funabiki K and Namba K: Antihypertensive effects of a new transdermal delivery system for clonidine (M-5041T) in spontaneously hypertensive rats. Arch Int Pharmacodyn Ther 327, 294-308 (1994)

12 Naruse $T$, Ishida $T$, Ishii $R$, Tagawa $T$ and Namba $K$ : Relationship between hypotensive effects and plasma concentrations of clonidine in spontaneously hypertensiverats: Continuous treatment of clonidine and sudden termination of clonidine infu- sion. Gen Pharmacol 25, 1421-1425 (1994)

13 Yamahata T, Dote S, Ozawa Y, Nishikawa $H$ and Maeda S: Determination of clonidine in human plasma by gas chromatography-electron-impact-mass spectrometry. J Chromatogr B Biomed Appl 653, 92-97 (1994)

14 Davidov M, Kakaviatos N and Finnerty FA: The antihypertensive effects of an imidazoline compound. Clin Pharmacol Ther $8,810-816$ (1967)

15 Hoobler S and Sagatsume E: Clonidine hydrochloride in the treatment of hypertension. Am J Cardiol 28, 67-73 (1971) 